Aletria, Belo Horizonte, v. 28, n. 1, p. 13-28, 2018

\title{
Entre dissonâncias e subversões: a experimentação formal nas narrativas de Ferréz e Claudio Galperin
}

\section{Between dissonances and subversions: formal experimentation in the narratives of Ferréz and Claudio Galperin}

\author{
Ana Paula Franco Nobile Brandileone \\ Universidade Estadual do Norte do Paraná, Cornélio Procópio, Paraná / Brasil \\ apnobile@uenp.edu.br \\ Mariângela Alonso \\ Universidade Estadual do Norte do Paraná, Cornélio Procópio, Paraná / Brasil \\ profalonso@uenp.edu.br
}

Resumo: Este artigo tem por objetivo discutir o deslocamento e a subversão dos conceitos mais tradicionais de gêneros literários, a partir dos contos "Pega ela", de Ferréz, e "Justiça", de Claudio Galperin. As questões levantadas analisam a potencialidade da experimentação formal de ambas as narrativas, procurando estabelecer relação de mediação com a realidade social em que foram produzidas. Por meio de diálogos dissonantes, a estrutura de "Pega ela" possibilita novas maneiras de pensar o modo narrativo dramático ao mimetizar a estrutura rítmica do rap, gerando ambiguidades e rejeições a convenções e formas. Do mesmo modo, "Justiça" aponta para a fragmentação narrativa que, ao fundir mecanismos e recursos expressivos ligados ao texto dramático e ao cinema, fraturam os constructos espaciais e temporais. No conjunto, tais estratégias convergem para a temática da violência na literatura brasileira contemporânea, na medida em que potencializam descontinuidades e rupturas como força criativa da ficção desses autores.

Palavras-chave: experimentação formal; Ferréz; Claudio Galperin. 


\begin{abstract}
This paper aims to discuss the displacement and the subversion of the most traditional concepts of literary genres, having as the object of study the short stories "Pega ela" by Ferréz and "Justice" by Claudio Galperin. The issues raised analyze the potentiality of the formal experimentation in both narratives, trying to establish a relation of mediation with the social reality in which they were produced. Through dissonant dialogues, the structure of "Pega ela" makes possible new ways of thinking the dramatic narrative by mimicking the rhythmic structure of the rap, resulting in ambiguities and rejections of conventions and methods. Likewise, "Justice" points to the narrative fragmentation that, by merging mechanisms and expressive resources connected to the dramatic text and to the cinema, breaks with spatial and temporal constructs. Taken together, these strategies converge to the theme of violence in the contemporary Brazilian literature, insofar as they enhance discontinuities and ruptures as the creative strength of these authors' fiction.
\end{abstract}

Keywords: formal experimentation; Ferréz; Claudio Galperin.

\title{
Pluralidade, diversidade e multiplicidade: marcas da produção literária contemporânea
}

A literatura brasileira contemporânea parece desafiar os estudos literários no que se refere à catalogação e à distinção das obras a partir do tradicional conceito de gêneros literários. Em tempos de crises política e identitária, as formas específicas e fixas não são mais capazes de inventariar a gama de produções presentes no cenário atual de nossas letras, haja vista a atuação das mudanças culturais e linguísticas incorporadas pelos jovens autores. No entanto, um lance de olhos a programas universitários de graduação em Letras evidencia, contrariamente, o cuidado descritivo e a presença da periodização literária.

É sabido que as catalogações periódicas e o estudo dos gêneros prestam-se a mecanismos de falseamento do ensino de Literatura, cujos procedimentos procuram articular a discussão das partes em sua relação com o todo, buscando modos ingênuos de sintetização da arte literária. Entretanto, o antagonismo contido em tais partes e os processos dialéticos presentes no cotidiano traumático encontram-se ausentes ou meramente falseados em tais catalogações.

Há que se dizer que a linguagem da modernidade é percorrida por uma gama de experiências traumáticas, tais como guerras, miséria e fome, aspectos que têm colocado em xeque a crença utópica de uma 
política protetora das massas. Tais situações tendem a modificar as relações sociais, na medida em que solicitam cada vez mais a afirmação dos indivíduos, questionando os estereótipos e as hierarquias erigidas equivocadamente. A partir de Adorno, ${ }^{1}$ pode-se afirmar que essas práticas antagônicas se realizam nas obras artísticas sob a ordem dos antagonismos formais, já que a fruição artística não ocorre apenas pelo consumo ou por ser algo desfrutável, mas sobremaneira pelos procedimentos contidos na sua lógica interna.

Nesse sentido, a hibridização de gêneros literários dá corpo à problemática da linguagem, bem como ao anticonvencionalismo temático como formas imediatas e recorrentes, os quais sinalizam e potencializam, no âmago da obra, a realidade problemática e complexa da atualidade. É nesse contexto que merece atenção o exame das metamorfoses ocorridas nos chamados gêneros literários e a averiguação de como essas formas apresentam-se na ficção brasileira contemporânea.

$\mathrm{O}$ tratamento dado aos gêneros literários pela produção ficcional atual não se define pela coexistência pacífica das diversas modalidades de romance e conto, dados o desdobramento e o deslocamento sofrido por estes gêneros que, incorporando outros gêneros, técnicas e linguagens dentro de suas fronteiras, confirmam o que há muito se sabe: as classificações são, em certa medida, artificiais. Essa fusão de gêneros, técnicas e linguagens resulta, muitas vezes, em textos indefinidos, os quais se acomodam dentro de um universo literário situado entre a tradição e a renovação. Nesse contexto é que as palavras de Antonio Candido podem ser adotadas para pensar a produção literária ficcional que hoje se faz no Brasil, ainda que se refira à prosa ficcional dos anos de 1970:

[...] romances que mais parecem reportagens; contos que não se distinguem de poemas ou crônicas, semeados de sinais e fotomontagens; autobiografias com tonalidade e técnica de romance; narrativas que são cenas de teatro; textos feitos com a justaposição de recortes, documentos, lembranças, reflexões de toda sorte. A ficção recebe na carne mais sensível o impacto do boom jornalístico moderno, do espantoso incremento de revistas e pequenos semanários, da propaganda, da televisão, das vanguardas poéticas $[\ldots] .^{2}$

${ }^{1} \mathrm{Cf}$. ADORNO. Teorias estéticas.

${ }^{2}$ CANDIDO. A nova narrativa, p. 209-210. 
Já para Tânia Pellegrini, ${ }^{3}$ o hibridismo do texto literário, na atualidade, tem a sua origem na invenção da fotografia e do cinema, os quais, segundo a autora, alteraram a nossa maneira de ver e perceber o mundo. Não por acaso, o texto literário vem sofrendo transformações em sua estrutura, evidente na fratura da linearidade da narrativa, fragmentação oriunda da contaminação das técnicas de enquadramento e montagem oriundas do cinema, ${ }^{4}$ a qual equivale, segundo Helena Bonito Pereira, ${ }^{5}$ ao espelho do próprio mundo fragmentado e caótico em que vivemos. Por isso, afirma Pellegrini ${ }^{6}$ em outro estudo, o texto literário é hoje um espaço de interações multidiscursivas, cujo objetivo é cada vez mais se aproximar da realidade do leitor e, assim, estabelecer um diálogo constante entre o real e o imaginário.

Ainda no que diz respeito ao hibridismo literário, Karl Erik Schøllhammer ressalta que a sua intensificação ganha força no início da década de 1990, gerando

[...] formas narrativas análogas às dos meios audiovisuais e digitais, tais como escritas roteirizadas de Patrícia Melo, Marçal Aquino e Fernando Bonassi, ou ainda a linguagem incorporada do universo da publicidade, como no romance Sexo (1999), de André Sant'Anna, ou no diálogo direto com a fogueira brasileira das vaidades midiáticas em Talk Show (2000), de Arnaldo Bloch, e no Controle remoto (2002), de Rafael Cardoso.?

Ainda que a fusão de gêneros literários e entre formas literárias e não literárias tenham se exacerbado na ficção brasileira contemporânea, a contestação do conceito tradicional de gênero literário inscreve-se nas possibilidades estéticas ditadas pelas vanguardas modernistas, de que Serafim Ponte Grande é um dos mais significativos romances. Utilizando a técnica cinematográfica e da bricolagem, justapondo os mais diversos materiais, numa profusão de cortes, recortes, montagens e numa combinatória parodística em que não somente a literatura, mas a própria existência é, por assim dizer, textualizada, Oswald de Andrade

${ }^{3}$ Cf. PELLEGRINI. Narrativa verbal e narrativa visual: possíveis aproximações.

${ }^{4}$ Cf. CUNHA. Mãos de cavalo e a permanência da literatura em tempos de midiatização digital.

${ }^{5}$ Cf. PEREIRA. Breves apontamentos para a história da literatura brasileira.

${ }^{6}$ Cf. PELLEGRINI. O outro lado do espelho: o simulacro na ficção de Sérgio Sant' anna.

${ }^{7}$ SCHØLLHAMMER. Ficção brasileira contemporânea, p. 38. 
rompe com certa modalidade do gênero narrativo ou da assim dita arte da prosa, compondo um não livro ou, nas palavras de Haroldo de Campos, ${ }^{8}$ um "romance-invenção".

Outro exemplo que remete à possibilidade infinita de recombinar, a partir do presente, o inventário interminável da tradição, é a miniaturização sofrida pelos procedimentos ficcionais, reflexo não só do leitor contemporâneo, que vive sob a pressão da urgência e do imediato, mas também do desdobramento das novas tecnologias. Ainda que assumindo um novo contorno na ficção brasileira contemporânea, esse artifício narrativo já foi empregado por Oswald de Andrade e Manuel Bandeira, por exemplo; hoje, tornou-se mais agudo e acentuado.

Nesse contexto, faz eco as considerações das organizadoras de $O$ futuro pelo retrovisor, as quais apontam para o olhar que a narrativa brasileira atual empreende rumo ao passado, "[...] operando reapropriações de questões fundamentais dos séculos XIX e XX - no plano estético, ideológico, temático, formal, etc. -, reelaboradas a partir do presente". ${ }^{9}$ É, então, saqueando da tradição literária o deslocamento sofrido pelos gêneros literários, que se pretende examinar, neste artigo, os contos de Claudio Galperin, "Justiça", e de Ferréz, "Pega ela", cujas subversões, descontinuidades e rupturas apontam para a força criativa e comunicativa de suas respectivas literaturas. Além disso, verificar a potencialidade dos experimentos formais, questionando em que medida tais experimentos estabelecem uma relação de mediação com a realidade social em que foram produzidos, associados que estão aos efeitos desumanos da violência social.

\section{Lapsos, fraturas e resistências: o hibridismo literário em "Pega ela", de Ferréz, e "Justiça", de Claudio Galperin}

Integrando a coletânea Ninguém é inocente em São Paulo, o conto "Pega ela", de Ferréz, elabora uma espécie de elogio à transgressão das formas literárias. $\mathrm{O}$ entrecho é todo construído pelos diálogos que ligam os dois personagens centrais, Lipo e Alemão, amigos de longa data. Em poucas linhas, o leitor torna-se testemunha de um conflito com desfecho violento, um assassinato motivado por traição, por meio de um acordo já

\footnotetext{
${ }^{8}$ Cf. CAMPOS. Serafim: um grande não-livro.

${ }^{9}$ CHIARELLI; DEALTRY; VIDAL. Apresentação, p. 7.
} 
aceito tacitamente: Alemão assassina Lipo por este ter se envolvido com a companheira do mandante e decreta que a mulher deva ser igualmente assassinada, visando a equidade do código. Assim, a morte da figura feminina é aí banalizada e inserida em um contexto de cruel indiferença, visto que é tomada conforme ao dever, em claro sinal de garantia de uma ordem provinda do elemento masculino:

Matei meu melhor amigo, meu companheiro, só que sua mulher também vacilou.

Eu sei, vou dar um coro nela.

Não basta, eu perdi meu irmão, você vai ter que matar ela.

Mas ela tá grávida.

Foda-se, de repente nem é seu, sabe o código, se não pegar, a gente pega você.

Tá, tá bom, carái, vou pegar. ${ }^{10}$

Ao escolher o modo de narrar por diálogos, o texto se afasta das formas mais tradicionais da narrativa, as quais eram mediadas por um narrador, o que solicita, de imediato, uma postura mais crítica e engajada do leitor. Com diálogos cortantes, o texto potencializa a dimensão de denúncia na medida em que sustenta uma fratura que parece estar fadada ao esgotamento social, já anunciada desde o início do conto. Ao modo de uma reunião de aforismos, as frases dos comparsas misturam ironia e suspense, construindo um universo ficcional de imagens perturbadoras ao leitor. Por não se constituir, portanto, um exemplar legítimo do conto tradicional, acionando recursos próprios do gênero dramático, o texto parece, ainda, mimetizar a estrutura rítmica do rap, gerando não apenas ambiguidade ao gênero, mas também provocando a rejeição a convenções e formas.

A formulação das frases assemelha-se ao ritmo do rap, musicalmente oriundo das classes urbanas periféricas, caracterizado por uma "[...] estrutura eminentemente discursiva e narrativa" ${ }^{11}$ Esse ritmo constitui-se como um movimento de afirmação das diferenças, capaz de enfocar com letras contundentes a plenitude abalada das comunidades marginalizadas. Tendo surgido nos Estados Unidos, mais especificamente

\footnotetext{
${ }^{10}$ FERRÉZ. Pega ela, p. 21-22.

11 DALCASTAGNÈ. A auto-representação de grupos marginalizados: tensões e estratégias na narrativa brasileira contemporânea, p. 29.
} 
nos guetos nova-iorquinos por comunidades de jamaicanos e afroamericanos, o rap possibilitou a discussão de problemáticas fulcrais, como a violência, o racismo, o tráfico de entorpecentes, a condição precária da educação, dentre outras. A exclusão social vivenciada por tais guetos propiciou a crítica e o embate frente ao engajamento político, capaz de dar novos sentidos ao cotidiano precário dos jovens, possibilitando a reedificação de suas identidades. Do inglês rhythm and poetry, o rap potencializa, pela linguagem, a indignação que resulta no tom contestatório das minorias. Desse modo, destacando-se das batidas e da própria melodia, a linguagem do rap cumpre seu papel apostando na improvisação de palavras rápidas e ferinas. Esse timbre artístico inserese, antes de tudo, em uma esfera ideológica, que recusa em primeira mão a melodia tradicional e harmônica para dar lugar ao texto e às vozes excluídas. Em tempos de opressão e desumanização, a música atinge com o rap uma postura de resistência e liberdade. Assim, tomado esteticamente em si mesmo, o rap já se opõe criticamente e estruturalmente a qualquer prisma paternalista de hierarquização e opressão sociais.

À luz do exposto, cabe considerarmos o contexto brasileiro no qual o rap ganha relevo como forma de resistência à indústria fonográfica:

[...] o rap brasileiro gerou seus próprios códigos e seus próprios espaços de consagração, à margem do mercado, da indústria fonográfica e da MTV - resistindo, até o momento com razoável êxito, às tentativas de cooptação. Ao contrário do que ocorre no campo literário, é o rapper branco, instruído, pequeno burguês, quem tenta mimetizar a dicção do marginalizado, mas sempre convive com o estigma de ser uma contrafação (basta pensar, por exemplo, em Gabriel, O Pensador). ${ }^{12}$

Nessa perspectiva, podemos entender o conto "Pega ela" em uma articulação possível com o ritmo rap, pois a elaboração formal do texto parece estar motivada por tensões deste contexto. O enlace entre estrutura e contexto é capaz de sustentar o elo profundo entre o modo de se relacionar com a linguagem e os embates sociais abordados por sua literatura. Conforme sentencia Adorno, "os antagonismos não resolvidos da realidade retornam às obras de arte como os problemas imanentes de

12 DALCASTAGNÈ. A auto-representação de grupos marginalizados: tensões e estratégias na narrativa brasileira contemporânea, p. 29. 
sua forma. É isto, e não a trama dos momentos objetivos, que define a relação da arte à sociedade". ${ }^{13}$

Em consonância com o que diz Adorno, encontramos entre os elementos formais trabalhados por Ferréz, a estetização da violência, esboçada por meio do ponto de vista, que se edifica por diálogos. Longe do paternalismo e da cosmovisão dos narradores tradicionais, o conto atua através do modo dramático que, antes de tudo está a serviço da representação de uma classe social complexa e oprimida.

Para além do simples contato entre dois indivíduos miseráveis, a narrativa ultrapassa o estatuto literário discursivo para ser lida e sentida como ato de transgressão e questionamento social. Nossa hipótese é de que o emprego da categoria do modo dramático seja importante como forma indicadora da precariedade dos sujeitos envolvidos na cena, vulneráveis a uma condição violenta e agônica. Assim, o texto elimina os estados mentais a partir do afastamento do narrador para dar voz e lugar aos diálogos lacônicos dos próprios personagens. Nas formulações de Norman Friedman, ${ }^{14}$ diríamos que o ângulo de visão procede ao modo frontal e fixo, com pequena distância entre o enredo e o leitor, uma vez que o conto segue por uma linha de cenas sucessivas. A cena possibilita a representação dramatizada, ao modo da técnica teatral, com frases breves e ritmadas, como se os personagens Lipo e Alemão atuassem ao modo de dois rappers:

\section{Longe, hein?}

É estrada, nego, é assim mesmo.

E como anda a Suzana?

A loira tá da hora.

Firmeza?

Por que a pergunta?

Saudade de vocês dois, porra. ${ }^{15}$

A partir daí a fluidez dos diálogos procede, com os comparsas relembrando os tempos antigos da amizade duradoura que os ligava intensamente, mantendo o que os rappers chamariam de flow, ${ }^{16}$ do

\footnotetext{
${ }^{13}$ ADORNO. Teoria estética, p. 16.

${ }^{14}$ Cf. FRIEDMAN. O ponto de vista na ficção: o desenvolvimento de um conceito crítico.

${ }^{15}$ FERRÉZ. Pega ela, p. 19.

${ }^{16}$ Cf. TEPERMAN. Improviso decorado.
} 
inglês 'fluxo', ou seja, a levada ou o encaixe dos versos na batida; até o momento em que algo "pega" entre os dois personagens, quebrando o clima amigável, como se vê na frase de Lipo: "Pára com essas coisas, Alemão, o que pega?"17

Os diálogos são empregados com um sentido poroso e perturbador, estrategicamente escritos em linguagem coloquial, com perguntas que acompanham as variações de humor dos personagens: negatividade, tranquilidade e suspense. Tais variações engendram fraturas que fogem aos recursos linguísticos dos contos mais tradicionais, com o destaque para gírias e palavrões empregados: "da hora", "porra". O elemento estético liga-se ao formal, uma vez que ambos estão implicados numa esfera reflexiva, desafiando o entendimento e a fruição do leitor.

O elo que mantém a amizade de Lipo e Alemão alinha-se à construção rítmica das frases, propiciando imagens perturbadoras e criadoras de impacto. As frases remetem às chamadas "batalhas de MC's", em que dois rappers (ao modo de mestres de cerimônia) "duelam” entre si através de rimas improvisadas ao som de uma batida, geralmente tocada por um DJ ou somente a capela, sem acompanhamento de bases musicais. Tais "batalhas" costumam ter a duração de 30 segundos para cada um dos participantes, podendo variar conforme o número de participantes. ${ }^{18}$ Não por acaso, Ferréz é ligado ao movimento hip hop e parece reivindicar com sua escrita uma espécie de tradição literária "às margens":

Nos seus livros e em entrevistas, insiste em marcar seu vínculo com Lima Barreto, Carolina Maria de Jesus e mesmo João Antônio. Assim, se apresenta não como alguém que almeja ser alçado à posição do "grande escritor universal", mas como aquele que briga nas bordas do campo literário. O que já era anunciado, de modo sarcástico, no seu primeiro livro: "Querido sistema, você pode até não ler, mas tudo bem, pelo menos viu a capa". ${ }^{19}$

${ }^{17}$ FERRÉZ. Pega ela, p. 20.

${ }^{18}$ Tais "batalhas" também são chamadas de freestyle. Na cidade de São Paulo, ocorrem frequentemente e em dias variados da semana, em bairros como Carandiru (Parque da Juventude), Vila Madalena (Batalha do Beco), Praça Roosevelt (Batalha da Roosevelt), Avenida São João (Batalha do Point), dentre outros. (Cf. AZEVEDO. Batalhas de rap: confronto de conhecimentos).

${ }^{19}$ DALCASTAGNÈ, A auto-representação de grupos marginalizados: tensões e estratégias na narrativa brasileira contemporânea, p. 29. 
A urdidura de "Pega ela" se faz por meio do drama de dois homens excluídos do sistema, os quais estão distantes da grandeza moral ou da ordem vigente burguesa. Em um contexto de dissipações e opressões, é exposta a destruição dos indivíduos por regras e códigos próprios. A violência constitui, por excelência, um processo vital de experiência e, por extensão, de formação do homem excluído. No entanto, para além da simples constatação da violência, o texto aposta no final demarcado pela negatividade, sem que se possa superar a experiência traumática da traição, que deverá ser punida à luz do código. Os diálogos aí são descritos reunindo suspense e agonia em uma enumeração que afasta a antiga amizade, mesclando violência e afetividade, uma vez que Alemão assassina Lipo e fecha o acordo de aniquilar também a mulher do mandante. Temos aí uma espécie de último $b e a t^{20}$ ou batida, que tende a funcionar no rap como o uso musical das pausas, finalizando o conto: "Sinto muito, Lipo [...]. Mas ela tá grávida. Foda-se, de repente nem é seu, cê sabe o código, se não pegar a gente pega vocês. Tá, tá bom, carái vou pegar". ${ }^{21}$

O conto então encerra-se como fratura dissonante e negativa, exprimindo a sentença de morte da figura feminina e, ao mesmo tempo, a violência, possibilitando com os diálogos novas possibilidades de pensar a teoria literária no que tange ao modo dramático, unindo forma e realidade social.

Importante destacar que a mobilização de recursos próprios ao texto teatral, foi inaugurado por Ferréz em 2006, com Ninguém é inocente em São Paulo; procedimento de escrita e trabalho de linguagem que será retomado na sua mais recente coletânea de contos, Os ricos também morrem, publicado em 2015. Tal procedimento preza pela estruturação dos contos em diálogos, produzindo uma espécie de esquete teatral que registra flashes do cotidiano, capturados pelo olhar atento e crítico do autor. Os textos, nessa perspectiva, se assemelham a fotografias que registram o cotidiano da periferia. Sem narradores, os contos são estruturados apenas pelo diálogo. A partir da interlocução dos personagens acompanhamos o registro de diferentes episódios da periferia, alguns marcados pela violência policial, outros por situações prosaicas de uma família. Desse

${ }^{20}$ TEPERMAN. Improviso decorado, p. 130.

${ }^{21}$ FERRÉZ. Pega ela, p. 21. 
modo, extraem-se os elementos que poderiam adensar o relato, restando apenas os personagens que representam a periferia urbana.

Publicado na antologia organizada por Nelson de Oliveira, Geração 90: os transgressores, a narrativa de Claudio Galperin, contrariamente à maioria da produção ficcional brasileira que toma a violência como objeto de análise e causa impacto pelo "realismo feroz", 22 "Justiça" agride o leitor pelos recursos técnicos que emprega, propondo soluções estéticas alternativas na sequência da narração, as quais tiram o leitor de sua passividade. $\mathrm{O}$ compromisso do autor com uma forma literária inovadora é aspecto notado por Karl Erik Schøllhammer. Figurando ao lado de outros escritores, como Luiz Ruffato, Nelson de Oliveira, Bruno Zeni, Marçal Aquino, Marcelino Freire, Joca Reiners Terron, Amilcar Bettega Barbosa e Ronaldo Brassane, o crítico afirma que todos

[...] conjugam os temas da realidade social brasileira ao compromisso com a inovação das formas de expressão e das técnicas de escrita. Abrindo, desta maneira, caminho para um outro tipo de realismo, cuja realidade não se apoia na verossimilhança da descrição representativa, mas no efeito estético da leitura, que visa envolver o leitor afetivamente na realidade da narrativa. ${ }^{23}$

Assim, para além da transposição da violência é a desintegração formal do texto que chama atenção no conto de Claudio Gasperin. "Justiça" narra um caso de estupro. Organizada em oito episódios, enumerados do fim para o início da história, a narrativa coloca de cabeça para baixo o encadeamento lógico de motivos e situações, que deve ser captado pelo leitor. Esses episódios são apresentados sem qualquer elo, pois a passagem de um episódio para outro é lacunar e sem qualquer mediação do narrador. As imagens oferecidas ao leitor parecem querer capturar os elementos essenciais dessa história; podendo inferir que a mesma passou por um processo de edição, o que remete, de pronto, à linguagem cinematográfica.

Desse modo, a narrativa constrói-se como um mosaico de fragmentos ou um "quebra-cabeça", que é gerado pelos vazios narrativos e por cortes abruptos no tempo e espaço diegéticos, bem como por múltiplos planos temporais e espaciais que se interpenetram,

${ }^{22}$ Cf. CANDIDO. A nova narrativa, p. 213.

${ }^{23}$ SCHØLLHAMMER. Ficção brasileira contemporânea, p. 59. 
comprometendo a coerência e contribuindo para a instauração do caos narrativo. Das elipses de tempo e de espaço, inscrevem-se os estilhaços de imagens trazidos por flashes cinematográficos, seja pela inserção dos diálogos entre a menina e o pedófilo, do diálogo do estuprador com a amante, da imagem de um homem nu numa câmara frigorífica (o pedófilo?) ou pela transcrição de uma reportagem de rádio, levando à ruptura da causalidade narrativa e, consequentemente, semeando dúvidas e ambiguidades:

sete

Km 72. Limite do município de Cruza das Almas.

No bagageiro do ônibus, escondida entre malas e caixas, uma Menina se pergunta quanto tempo ainda falta para chegar em Jaboticabal.

seis

Câmara frigorífica. Ampla. Gelada.

Corrente do teto terminando em ganchos. Peças de carne suspensas.

O cadáver do Homem mutilado, sem roupa, estendido no chão. ${ }^{24}$

A fragmentação da narrativa gerada pelo uso de recursos cinematográficos leva, portanto, à destruição da cronologia linear e a reconstrução dos fatos em constructos espaciais, desaparecendo, desse modo, os limites entre espaço e tempo, numa infinita e ilimitada corrente de interrelações que corresponde exatamente à mistura de espaço e tempo. A espacialização do tempo, no texto, ocorre devido à fragmentação dos fatos que, numa narrativa tradicional, apareceriam em sequência.

Além do diálogo estabelecido com a linguagem cinematográfica, resultando na fragmentação do discurso literário, o conto mobiliza um outro recurso estilístico, agora ligado à arte dramática: a ausência do narrador. Não por acaso, a narrativa mais parece um roteiro teatral, tradicionalmente assentado na abolição do narrador e na combinação de diálogo e didascália e/ou denominada rubrica, que são as marcações cênicas:

${ }^{24}$ GALPERIN. Justiça, p. 195. 
um

Galhos de árvore, materiais reciclados. Um precário abrigo do mato.

- Gostou?

- Que cabana bonita!

- Castelo!

- Castelo!

- Vem... Entra...

A Menina, com facilidade. O Homem fazendo do corpo um arco. ${ }^{25}$

Tornada a ação representação, uma vez que o "contar" é substituído pelo "mostrar", os personagens tornam-se atores do drama levado em cena, resultando, portanto, em uma estratégia de representação afim da representação dramática propriamente dita, o que naturalmente implica na supressão do narrador, base da narrativa tradicional.

A adoção de procedimentos que se aproximam da técnica cinematográfica, dada a justaposição dos fatos e da técnica de corte e montagem, cuja apreensão se faz por analogia, bem como a presença da oralidade, que advém da qualidade na construção dos diálogos, está diretamente relacionada à atividade de roteirista que Galperin realiza, participando de diferentes produções de séries televisivas, como Antônia, de 2006, pela TV Globo, e produções cinematográficas, como o filme $O$ ano que meus pais saíram de casa, também de 2006, dirigido por Cao Hamburger.

Dada subordinação da literatura brasileira contemporânea à realidade, não raro, ao "mundo cão", a literatura brasileira contemporânea não se quer mais mediação, isto é, lugar de passagem, de trânsito, de possibilidades; mas imediação, porque quer de um lado apresentar-se como reprodução imediata do dado real e, de outro, se colocar ao leitor a partir de uma relação direta com o mundo (realidade elevada à máxima potência), o que explicaria, segundo Brandileone, ${ }^{26}$ o desaparecimento do narrador. No caso do conto aqui analisado, pode-se dizer que a ausência do narrador é estratégia para deixar o leitor "cara a cara" com a violência, figurada pelo estupro (ou quase) de Geovana, menina de nem seis anos de idade.

${ }^{25}$ GALPERIN. Justiça, p. 198.

${ }^{26}$ Cf. BRANDILEONE. Literatura brasileira contemporânea: caminhos diversos. 
Dentre as imagens trazidas em fragmento, ganha destaque a inclusão de um registro diferente, não literário, expresso por diferentes vozes que, aflitas e revoltadas com o caso, pedem a punição do estuprador; aspecto do texto que dissolve as fronteiras claras entre a ficção e a não ficção:

dois

Rádio Guarani. 90,7 AM.

"Ele tava daquele jeito, com a filhinha da Dora, antes dela sumir de novo..."

"A mãe coitada... Imagina... Estuprar uma menina, meu Deus! Nem seis anos ela tinha..."

"Uma hora dessas acabam achando o corpo da menina... Num terreno baldio, num buraco no meio do mato... Tem vez que demora pra achar... Outras vezes num acha..."

"Tem gente aqui que não vai deixar de graça não... Eu num vou dizer quem, mas vão acabar encontrando esse homem. Homem não, bicho! Uma hora pegam ele..."

"Cadeia!? Tem que esfolar o filhodaputa!"27

O rompimento com a serialidade linear dos acontecimentos, de modo a não permitir distinguir o que aconteceu antes do que aconteceu depois (apenas inferir), desmonta a premissa representativa e mimética, abrindo caminho para um outro tipo de realismo, cuja realidade não se apoia na verossimilhança da descrição representativa, mas no efeito estético da leitura, que visa envolver o leitor afetivamente na realidade da narrativa.

Desse modo, a liberdade experimental acionada por Galperin para a construção literária, dada a sua opção pelo fragmentário e pela mobilização de mecanismos e recursos expressivos ligados à dramaturgia e ao cinema, permite que o conto se diferencie da tônica brutalista da literatura brasileira hoje. Não por acaso é que Karl Erik Schøllhammer ${ }^{28}$ defende que a ficção brasileira contemporânea, nem diferente nem melhor na relação estabelecida com os meios de comunicação social na sua sede de nos superexpor à realidade ou, como quer o autor, à "vida como ela é", tem

${ }^{27}$ GALPERIN. Justiça, p. 198.

${ }^{28} \mathrm{Cf}$. SCHØLLHAMMER. Ficção brasileira contemporânea. 
o desafio " $[. .$.$] de encontrar outra expressão de realidade não apropriada$ e esvaziada pela indústria do realismo midiático". ${ }^{29}$

Missão assumida com maestria por Ferréz e Galperin que, ao conjugar a temática da violência ao compromisso com a inovação da forma de expressão e da técnica de escrita, criam um efeito literário e estético que se de um lado coloca a realidade social brasileira na ordem do dia, de outro, não se rende à especularização e à espetacularização da violência, tendência e marca da ficção brasileira contemporânea. $O$ que fica são textos que penetram com vigor no leitor, mas que não se deixam avaliar com facilidade.

\section{Referências}

ADORNO, Theodor. Teoria estética. Tradução de Artur Mourão. São Paulo: Martins Fontes, 1986.

AZEVEDO, Rafael. Batalhas de rap: confronto de conhecimentos. Revista Arruaça, São Paulo, n. 4, jan. 2016. Disponível em: <https:// casperlibero.edu.br/revista-arruaca/batalhas-de-rap-confronto-deconhecimentos/>. Acesso em: 19 mar. 2018.

BRANDILEONE, Ana Paula Franco Nobile. Literatura brasileira contemporânea: caminhos diversos. In: BRANDILEONE, Ana Paula Franco Nobile; OLIVEIRA, Vanderléia da Silva. Desafios contemporâneos: a escrita do agora. São Paulo: AnnaBlume, 2013. p. 17-33.

CAMPOS, Haroldo de. Serafim: um grande não-livro. In: ANDRADE, Oswald de. Serafim Ponte Grande. 9. ed. São Paulo: Globo, 2007. p. 13-46.

CANDIDO, Antonio. A nova narrativa. In: e outros ensaios. São Paulo: Ática, 1987. p. 199-215. . A educação pela noite

CHIARELLI, Stefania; DEALTRY, Giovanna; VIDAL, Paloma. Apresentação. In: Rocco, 2013. p. 7-14. . O futuro pelo retrovisor. Rio de Janeiro:

${ }^{29}$ SCHØLLHAMMER. Ficção brasileira contemporânea, p. 57. 
CUNHA, João Manuel dos Santos. Mãos de cavalo e a permanência da literatura em tempos de midiatização digital. In: PEREIRA, Helena Bonito (Org.). Novas leituras da ficção brasileira no século XXI. São Paulo: Universidade Presbiteriana Mackenzie, 2011. p. 197-224.

DALCASTAGNÈ, Regina. A auto-representação de grupos marginalizados: tensões e estratégias na narrativa contemporânea. Revista Letras de Hoje, Porto Alegre, v. 42, n. 4, p. 18-31, 2007.

FERRÉZ. Pega ela. In: de Janeiro: Objetiva, 2006. p. 19-22.

. Ninguém é inocente em São Paulo. Rio

FRIEDMAN, Norman. O ponto de vista na ficção: o desenvolvimento de um conceito crítico. Tradução de Fábio Fonseca de Melo. Revista USP, São Paulo, n. 53, p. 166-182, mar.-maio 2002.

GALPERIN, Claudio. Justiça. In: OLIVEIRA, Nelson de. Geração 90: os transgressores. São Paulo: Boitempo Editorial, 2003. p. 195-200.

PELLEGRINI, Tânia. Narrativa verbal e narrativa visual: possíveis aproximações. In: et al (Org.). Literatura, cinema e televisão. São Paulo: Senac; Instituto Itaú Cultural, 2003. p. 15-35.

PELLEGRINI, Tânia. O outro lado do espelho: o simulacro na ficção de Sérgio Sant'anna. In: . Despropósitos: estudos da ficção contemporânea. São Paulo: FAPESP; AnnaBlume, 2008. p. 101-116.

PEREIRA, Helena Bonito. Breves apontamentos para a história literária brasileira. In: . (Org.). Novas leituras da ficção brasileira do século XXI. São Paulo: Universidade Presbiteriana Mackenzie, 2011. p. 31-49.

SCHØLLHAMMER, K. Erik. Ficção brasileira contemporânea. 2. ed. Rio de Janeiro: Civilização Brasileira, 2011.

TEPERMAN, Ricardo Indig. Improviso decorado. Revista do Instituto de Estudos Brasileiros, São Paulo, USP, n. 56, p. 127-150, jun. 2013.

Recebido em: 16 de dezembro de 2017.

Aprovado em: 9 de março de 2018. 